\title{
МОДЕЛЮВАННЯ ЗАЛЕЖНОСТЕЙ «БАГАТОВИМІРНИЙ ВХІД-ВИХІД» ДЛЯ АВТОМАТИЗАЦІЇ ПРОЦЕСІВ КЕРУВАННЯ В УМОВАХ НЕВИЗНАЧЕНОСТІ
}

\section{Рецензент - доктор технічних наук В. П. Дмитриков}

Розглянута у роботі технологія дає змогу иляхом поєднання переваг м'яких обчислень і ретресійного аналізу будувати багатофакторні залежності з неперервним виходом, враховуючи як можливість визначення ступеня важливості вхідних змінних, так $і$ їх взаємодій необхідного порядку. Проте під час моделювання об'єктів із неперервним виходом, коли необхідна достатня точність визначення чіткого значення вихідної величини, знаходження параметрів нечіткого рівняння регресї за методом наймениих квадратів та параметрів функиій належностей иляхом статистичної обробки експертної інформачії не може в повній мірі забезпечити потрібну точність. Для цьього потрібно налаштувати за навчальною вибіркою нечітку регресійну модель у відповідності до тестуючої вибірки.

Ключові слова: багатофакторна залежність, множсинна ретресія, нечіткий логічний висновок, м'які обчислення, функиії належності, (лінгвістичні) змінні.

Постановка проблеми. Технологічні процеси, що розглядаються в різних областях виробництва, не завжди можуть мати адекватний аналітичний опис через недостатню вивченість їх внутрішніх особливостей. Під час вирішення практичних завдань досить часто виникає необхідність побудови залежності «багато входів - один вихід» [1] за експериментальними даними. У разі функції однієї змінної побудова такої залежності не викликає ніяких труднощів: за набором точок на площині завжди можна підібрати криву, що адекватно відображає існуючий зв'язок між змінними. Завдання ускладнюється у випадку збільшення числа вхідних параметрів, що впливають на вихідну величину. Це пояснюється тим, що практично неможливо підібрати поверхню, що реально відображає залежність між змінними.

Аналіз останніх досліджень і публікацій, у яких започатковано розв'язання проблеми. Для розв'язання неформалізуємих задач визначення багатовимірної залежності «входи-вихід», за наявності нечіткої інформації, застосовується метод моделювання нечіткими базами знань, що визначають причинно-наслідкові зв'язки між вхідними змінними та вихідною величиною. Водночас застосовується принцип двоетапного на- лаштування баз нечітких знань. У відповідності до цього принципу побудова моделі нелінійного об'єкта здійснюється у два етапи, які є аналогією етапів структурної і параметричної ідентифікації, характерних для класичних методів [2, 6].

Перший етап складається 3 формування за експертною інформацією моделі об'єкта шляхом побудови бази знань та грубого налаштування цієї моделі [2-4]. Такий підхід є традиційним для нечітких систем і не гарантує збіг теоретичних і експериментальних даних. Другий етап необхідний для проведення тонкого налаштування нечіткої моделі шляхом іiі навчання за експериментальними даними. Навчання моделі полягає у підборі параметрів функцій належності і вагових коефіцієнтів правил «Якщо - тоді» шляхом мінімізації різниці між бажаними експериментальними і теоретичними даними. Навчання нечіткої моделі доцільно проводити методами еволюційного програмування - генетичними алгоритмами, які $\epsilon$ аналогом випадкового пошуку з використанням операцій схрещення, мутації та селекції [2-8].

Метою дослідження $\epsilon$ розробка теоретичних аспектів проблеми ідентифікації та керування складними технічними системами в умовах невизначеності за допомогою нечітких моделей та адаптивних алгоритмів.

Предметом дослідження є математичні алгоритми i програми автоматичного керування складними технічними системами в умовах інформаційної невизначеності.

Методи дослідження включають моделі та методи нечіткої логіки, штучні нейронні мережі, генетичні алгоритми, адаптивне керування складними технічними системами в умовах невизначеності.

Результати дослідження. Труднощі, позначені в постановці проблеми, певною мірою вдається вирішувати для окремих випадків шляхом використання лінійного рівняння регресії. Багатофакторна залежність, що пов'язує контрольовані параметри з результативною ознакою, може бути представлена наступним рівнянням множинної регресії: 


$$
y=a_{0}+a_{1} \cdot x_{1}+a_{2} \cdot x_{2}+\ldots+a_{i} \cdot x_{i}+\ldots+a_{n} \cdot x_{n},
$$

де $a_{0}, a_{1}, \ldots a_{n}$ - невідомі коефіцієнти регресії.

Під час врахування парних взаємодій, які часто задовольняють певній моделі, рівняння регресії стає нелінійним за факторами:

$$
\begin{aligned}
& y=a_{0}+a_{1} \cdot x_{1}+a_{2} \cdot x_{2}+\ldots+a_{i} \cdot x_{i}+\ldots+a_{n} \cdot x_{n}+a_{12} x_{1} x_{2}+ \\
& +a_{13} x_{1} x_{3}+\ldots+a_{i_{1} i_{2}} x_{i_{1}} x_{i_{2}}+\ldots+a_{n-1 n} x_{n-1} x_{n}=\sum_{i=1}^{n} a_{i} x_{i}+\sum_{i_{1}=1}^{n} \sum_{i_{2} \neq i_{1}} a_{i_{1} i_{2}} x_{i_{1}} x_{i_{2}}
\end{aligned}
$$

Головним недоліком такого моделювання $\epsilon$ те, що в рівняннях розглянутого типу вхідні змінні мають лише числову природу, але у багатьох випадках в умовах наявності лінгвістичної інформації на результативну ознаку мають великий вплив і якісні фактори з великим числом градацій.

Проблему врахування якісної інформації вирішують введенням у рівняння фіктивних змінних. Як фіктивні змінні використовують дихотомічні (бінарні) змінні, які набувають двох значень: 0 та 1. Із введенням фіктивних змінних регресійна модель матиме вигляд:

$$
y=a_{0}+a_{1} \cdot x_{1}+a_{2} \cdot x_{2}+\ldots+a_{i} \cdot x_{i}+\ldots+a_{n} \cdot x_{n}+\alpha_{1} z_{1}
$$

Якщо якісна ознака, що розглядається, має $k$ градацій, то в модель можна ввести дискретну змінну, яка набуває стільки ж значень. Зазвичай у модель вводять $(k-1)$ бінарних змінних:

$$
\begin{gathered}
y=a_{0}+a_{1} \cdot x_{1}+a_{2} \cdot x_{2}+\ldots+a_{i} \cdot x_{i}+\ldots+a_{n} \cdot x_{n}+\alpha_{1} z_{1}+\ldots+\alpha_{k-1} z_{k-1}, \\
\text { де } z_{i}= \begin{cases}1, & \text { якщо ознака належить } i+1-\text { му рівню } \\
0, & \text { в іншому випадку }\end{cases}
\end{gathered}
$$

За такого підходу число бінарних змінних повинно бути на 1 менше числа градацій якісної змінної.

Розглянуті підходи залишили проблему наявності нечітко заданої інформації: неможливість врахування якісних (лінгвістичних) змінних, що мають нечіткий характер, та неможливість точного вимірювання кількісних змінних.

Альтернативою існуючим підходам щодо апроксимації багатовимірної залежності $\epsilon$ апарат нечіткої математики, яка мала бурхливий розвиток в 90-х рр. минулого сторіччя і величезний попит в азіатських країнах, особливо в Японії. Останнім часом величезним попитом користується практичне застосування розроблених підходів з використанням Fuzzy logic.

Найбільшого розповсюдження за нечіткого моделювання отримали підходи, засновані на нечіткому логічному висновку за алгоритмами Мамдані, Ларсена та Такагі-Сугено. Апроксимація нелінійних залежностей за нечітким логічним висновком, як і будь-які методи моделювання, має певні недоліки, серед яких найбільш істотними є наступні [3]:

- продукційні правила не передбачають можливості врахування ступеню впливу вхідних змінних на результативну ознаку;

- система нечіткого логічного висновку, особливо у випадку великої кількості вхідних змінних, може у деяких випадках, за малих значень функцій належності вхідних змінних до їх термів, отримати неточні розрахунки;

- у процедурі нечіткого логічного висновку відсутня можливість врахування між вхідними змінними взаємодій будь-якого порядку.

Останнім часом все більш актуальним стає тенденція комплексного підходу до різних методів моделювання із застосуванням сучасних інтелектуальних технологій, що дає змогу подолати певні труднощі використання кожного 3 них окремо. Одним із таких сучасних напрямів $\epsilon$ «Soft Computing», що поєднує нечітку логіку, нейронні мережі, генетичні обчислення та інші технології. Однак залишаються ще нерозв'язаними багато проблем, серед яких і ті, що розглянуті вище. 


\section{TEХНIЧНI НАУКИ}

У роботі [3] запропонований підхід, що дає можливість подолати перелічені труднощі у задачах класифікації, тобто за якісної результативної ознаки, за рахунок комплексного використання м'яких обчислень та регресійного аналізу. Однак питання побудови багатофакторної зале- жності із неперервним виходом залишається нерозглянутим.

Класичний регресійний аналіз дає змогу будувати багатовимірні залежності за експериментальною матрицею даних $X$, що має наступний вигляд:

$$
X=\left(\begin{array}{cccccc|c}
x_{11} & x_{12} & \ldots & x_{1 i} & \ldots & x_{1 n} & y_{1} \\
x_{21} & x_{22} & \ldots & x_{2 i} & \ldots & x_{2 n} & y_{2} \\
\ldots & \ldots & \ldots & \ldots & \ldots & \ldots & \ldots \\
x_{l 1} & x_{l 2} & \ldots & x_{l i} & \ldots & x_{1 n} & y_{l} \\
\ldots & \ldots & \ldots & \ldots & \ldots & \ldots & \ldots \\
x_{N 1} & x_{N 2} & \ldots & x_{N i} & \ldots & x_{N n} & y_{N}
\end{array}\right)
$$

Значення вихідної змінної розіб’ємо на $m$ підінтервалів:

$$
[\underline{y}, \bar{y}]=\underbrace{\left[y, y_{1}\right.}_{d_{1}}) \cup \underbrace{\left[y_{1}, y_{2}\right)}_{d_{2}} \cup \ldots \cup \underbrace{\left[y_{j-1}, y_{j}\right.}_{d_{j}}) \cup \ldots \cup \underbrace{\left[y_{m-1}, \bar{y}\right.}_{d_{m}}] .
$$

Розглянемо можливість використання для кожного із цих інтервалів нелінійного рівняння регресії:

$$
y_{j}^{l}=\sum_{i=1}^{n} a_{i}^{j} z_{i}^{j l}+\sum_{i_{1}=1}^{n} \sum_{i_{2} \neq i_{1}} a_{i_{1} i_{2}}^{j} z_{i_{1}}^{j l} z_{i_{2}}^{j l}+\sum_{i_{1}=1}^{n} \sum_{i_{2} \neq i_{1} i_{2} \neq i_{1} \neq i_{3}} \sum_{i_{1} i_{2}}^{j} z_{i_{1}}^{j l} z_{i_{2}}^{j l} z_{i_{3}}^{j l}+\ldots
$$

де $z_{i}^{j l}$ - число, що встановлює, якою мірою значення $x_{l i}$ змінної $x_{i}$ в $l$-ому експерименті сприятливо для попадання значення вихідної змінної в $j$-ий підінтервал, $z_{i}^{j l} \in[0,1]$.

Тут $y_{j}^{l}$ - число, що встановлює ступінь належності вихідної змінної $j$-ому підінтервалу за певних значень вхідних змінних $l$-го експерименту.

Для полегшення розрахункових процедур уведемо наступні позначення. Коефіцієнти $j$-го рівняння регресії будемо шукати за матрицею, що відповідає $j$-ому інтервалу:

$$
H_{j}=\left(\begin{array}{cccccccccccccc}
z_{1}^{j 1} & z_{2}^{j 1} & \ldots & z_{i}^{j 1} & \ldots & z_{n}^{j 1} & z_{1}^{j 1} z_{2}^{j 1} & z_{1}^{j 1} z_{3}^{j 1} & \ldots & z_{i_{1}}^{j 1} z_{i_{2}}^{j 1} & \ldots & z_{n-1}^{j 1} z_{n}^{j 1} & \ldots \\
z_{1}^{j 2} & z_{2}^{j 2} & \ldots & z_{i}^{j 2} & \ldots & z_{n}^{j 2} & z_{1}^{j 2} z_{2}^{j 2} & z_{1}^{j 2} z_{3}^{j 2} & \ldots & z_{i_{1}}^{j 2} z_{i_{2}}^{j 2} & \ldots & z_{n-1}^{j 2} z_{n}^{j 2} & \ldots \\
\ldots & \ldots & \ldots & \ldots & \ldots & \ldots & \ldots & \ldots & \ldots & \ldots & \ldots & \ldots & \ldots \\
z_{1}^{j l} & z_{2}^{j l} & \ldots & z_{i}^{j l} & \ldots & z_{n}^{j l} & z_{1}^{j l} z_{2}^{j l} & z_{1}^{j l} z_{3}^{j l} & \ldots & z_{i_{1}}^{j l} z_{i_{2}}^{j l} & \ldots & z_{n-1}^{j l} z_{n}^{j l} & \ldots \\
\ldots & \ldots & \ldots & \ldots & \ldots & \ldots & \ldots & \ldots & \ldots & \ldots & \ldots & \ldots & \ldots \\
z_{1}^{j N} & z_{2}^{j N} & \ldots & z_{i}^{j N} & \ldots & z_{n}^{j N} & z_{1}^{j N} z_{2}^{j N} & z_{1}^{j N} z_{3}^{j N} & \ldots & z_{i_{1}}^{j N} z_{i_{2}}^{j N} & \ldots & z_{n-1}^{j N} z_{n}^{j N} & \ldots
\end{array}\right)
$$

Матрицю невідомих параметрів моделі (3) запишемо у вигляді:

$$
A_{j}^{T}=\left(\begin{array}{llllllllllll}
a_{1}^{j} & a_{2}^{j} & \ldots & a_{n}^{j} & a_{12}^{j} & a_{13}^{j} & \ldots & a_{i_{1} i_{2}}^{j} & \ldots & a_{n-1 n}^{j} & \ldots & a_{1 \ldots n-1 n}^{j}
\end{array}\right), j=\overline{1, m} .
$$

Матриця значень вихідної змінної у нечіткій формі має вигляд: 


$$
Y_{j}^{T}=\left(\begin{array}{llllll}
y_{j}^{1} & y_{j}^{2} & \ldots & y_{j}^{l} & \ldots & y_{j}^{N}
\end{array}\right),
$$

де $y_{j}^{l}=\mu^{d_{j}}\left(X_{l}\right)$ - число, що встановлює, в якій мірі сприятливо попадання значення вихідної змінної у $j$-ий підінтервал, коли набір вхідних змінних утворює вектор $X_{l}, y_{j}^{l} \in[0,1]$.

Це число можна розраховувати за допомогою нечіткого логічного висновку в залежності від досвіду його використання за одним із відомих алгоритмів, як значення функції належності за таких векторів вхідних змінних, за яких воно $\epsilon$ більшим, ніж 0,5 , щоб уникати проблем, розглянутих вище.

Тоді у матричній формі модель (3) буде мати вигляд $Y_{j}=H_{j} A_{j}$.

Для кожного з інтервалів будуватимемо рівняння регресії, коефіцієнти яких шукатимемо за допомогою методу найменших квадратів:

$$
A_{j}=\left(H_{j}{ }^{T} H_{j}\right)^{-1} H_{j}{ }^{T} D_{j}, j=\overline{1, m}
$$

Значення $z_{i}^{j l}$ матриці $H_{j}$ розраховуються за функціями належності $\mu_{j}\left(x_{i}\right)$ вхідної змінної $x_{i}$ нечіткій множині значень, сприятливих попаданню вихідної змінної у $j$-ий підінтервал. Тому вихідну змінну моделі (3) доцільно представити також функцією належності такого ж типу, що і функція $\mu_{j}\left(x_{i}\right)$.

Для обчислення функції належності $\mu^{d_{j}}(y)$ вихідної змінної необхідно застосовувати операції над нечіткими числами.

Якщо використовувати дзвіноподібну модель функції належностей

$$
\mu^{T}(x)=\left(1+\left(\frac{x-b}{c}\right)^{2}\right)^{-1},
$$

що має тільки два параметри настроювання: $b$ - координата максимуму функції та $c$ - коефіцієнт розтягування, тоді функції належності $\mu^{d_{j}}(y)$ вихідної змінної можна записати у вигляді:

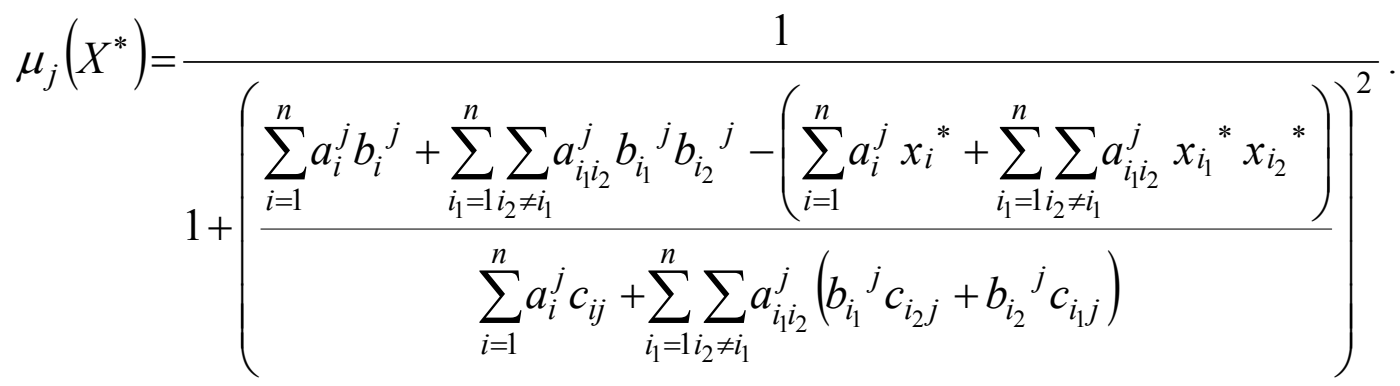

Після обчислення значень функції $\mu^{d_{j}}(y)$ за кожним із підінтервалів за фіксованого вектора вхідних змінних необхідно для знаходження чіткого числа провести операцію дефазифікації. Для цього доцільно розбити інтервал $[\underline{y}, \bar{y}]$ наступним чином: $y_{1}=\underline{y}+\Delta, y_{2}=\underline{y}+2 \Delta, \ldots, y_{m-1}=\bar{y}-\Delta$, $\Delta=\frac{\bar{y}-\underline{y}}{m-1}$.

Із застосуванням розбиття інтервалу $[y, \bar{y}]$ формула дефазифікації за методом центру тяжіння має вигляд: 


$$
y^{*}=\frac{\sum_{j=1}^{m}[\underline{y}+(j-1) \Delta] \mu^{d_{j}}(y)}{\sum_{j=1}^{m} \mu^{d_{j}}(y)} .
$$

На другому етапі доцільно провести параметричну ідентифікацію отриманої нечіткої регресійної моделі шляхом настроювання iï параметрів генетичними алгоритмами та за допомогою нейронних мереж.

Задача настроювання моделі (1) складається у підборі для кожного з інтервалів вихідної змінної таких значень векторів параметрів $A_{j}^{T}=\left(\begin{array}{llllllllll}a_{1}^{j} & a_{2}^{j} & \ldots & a_{n}^{j} & a_{12}^{j} & a_{13}^{j} & \ldots & a_{i_{1} i_{2}}^{j} & \ldots & a_{n-1 n}^{j}\end{array}\right)$, $j=\overline{1, m}$ та параметрів функцій належностей, тобто вектора

$S=\left(b_{11}, c_{11}, b_{12}, c_{12}, \ldots, b_{i 1}, c_{i 1}, \ldots, b_{i m}, c_{i m}, \ldots, b_{n 1}, c_{n 1}, b_{n 2}, c_{n 2}, \ldots, b_{n m}, c_{n m}\right)$,

які мінімізували б різницю між модельним та еталонним результатом [3, 4]:

$$
\sum_{l=1}^{M}\left\{\sum_{j=1}^{m}\left[F_{y}\left(X^{l}, A, B, C\right)-y^{l}\right]^{2}\right\}=\min _{B, C} .
$$

Таку параметричну ідентифікацію можна здійснити за навчальною вибіркою генетичними алгоритмами, де хромосомою буде виступати вектор, що складається із компонентів векторів $A_{j}$ та $S=(B, C)$. Процедура такого налаштування полягає у знаходженні таких генів хромосом шляхом проведення операцій схрещування та мутації [5], які забезпечували б умову (7).

Висновок. Розглянута технологія дає змогу шляхом поєднання переваг м'яких обчислень і регресійного аналізу будувати багатофакторні залежності з неперервним виходом, враховуючи як можливість визначення важливості вхідних змінних, так і їх взаємодій необхідного порядку. Однак під час моделювання об'єктів із неперервним виходом, коли необхідна достатня точність визначення чіткого значення вихідної величини, знаходження параметрів нечіткого рівняння регресії за методом найменших квадратів та параметрів функцій належностей шляхом статистичної обробки експертної інформації не може в повній мірі забезпечити потрібну точність. Таким чином, потрібно налаштувати за навчальною вибіркою нечітку регресійну модель у відповідності до тестуючої вибірки.

\section{БІБЛІОГРАФІЯ}

1. Лєві Л. І. Інтелектуальні технології моделювання залежностей «Багатовимірний вхід-вихід» / Л. І. Лєві, А. В. Тащіліна : матеріали міжнар. наук. конф. Том 2 [«Інтелектуальні системи прийняття рішень і проблеми обчислювального інтелекту»]. - Херсон : ХНТУ, 2010. - С. 98-101.

2. Ротштейн А. П. Интеллектуальные технологии идентификации: нечеткие множества, генетические алгоритмы, нейронные сети / А. П. Ротштейн. - Вінница : Універсум-Вінниця, 1999. $320 \mathrm{c.}$

3. Ротштейн О. П. Soft Computing в біотехнології: багатофакторний аналіз і діагностика / О. П. Ротштейн, С. П. Ларюшкін, Ю. І. Мітюшкін. - Вінниця : Універсум-Вінниця, 2008. - 144 с.

4. Ротштейн А. П. Извлечение нечетких баз знаний из экспериментальных данных с помо- щью генетических алгоритмов / А. П. Ротштейн, Ю. И. Митюшкин // Кибернетика и системный анализ. - 2001. - №4. - С. 45-53.

5. Тащилин M. B. Нечеткая экспертная система с регрессионным механизмом логического вывода / М. В. Тащилин, Т. И. Каткова // Вісник Національного технічного університету ХПІ. Х. : НТУ «ХПІ», 2009. - №4. - С. 69-75.

6. Штейнберг Ш. Е. Идентификация в системах управления / Ш. Е. Штейнберг. - М. : Энергоатомиздат, 1987. $-81 \mathrm{c}$.

7. Штовба С. Д. Проектирование нечетких систем средствами MATLAB / С. Д. Штовба. М. : Горячая линия Телеком, 2007. -288 с.

8. Gen M. Genetic Algorithms and Engineering Design / M. Gen, R. Cheng. - New York : John Wiley \& Sons, 1997. -352 p. 